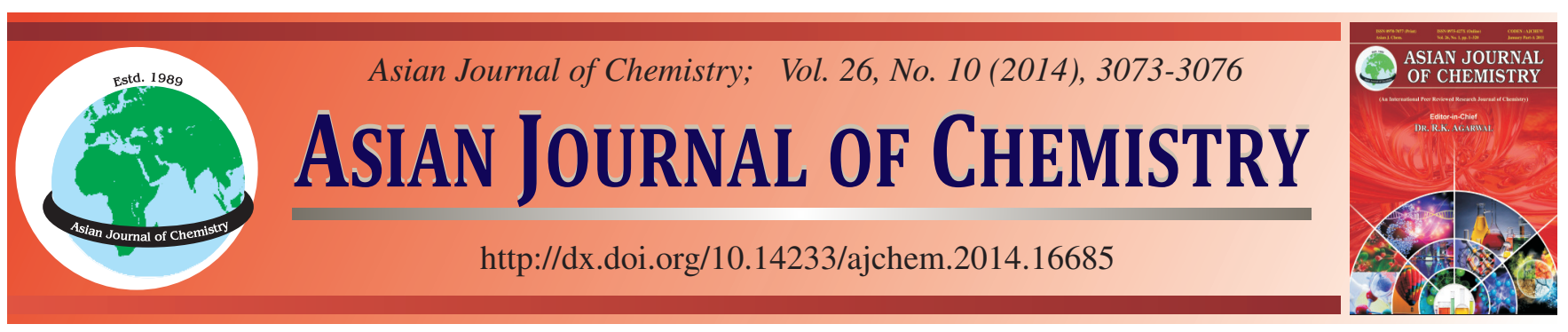

\title{
Evaluation of Antioxidant Activity of Polysaccharides from Tussilago farfara L. by Flow Injection Analysis
}

\author{
Kun Qin ${ }^{1}$, CAinong Liu ${ }^{2, *}$, YongXiu QI ${ }^{2}$ and $\mathrm{Ke} \mathrm{Li}^{2}$
}

${ }^{1}$ College of Chemistry and Chemical Engineering, Taishan Medical University, Tai'an 271016, P.R. China

${ }^{2}$ College of Pharmaceutical, Taishan Medical University, Tai'an 271016, P.R. China

*Corresponding author: E-mail: liuch7688@163.com

Received: 13 November 2013;

Accepted: 24 Janaury 2014;

Published online: 10 May 2014;

AJC-15183

\begin{abstract}
In this study, water-soluble crude polysaccharides from Tussilago farfara L. and the polysaccharides, deproteinized and decolorized from the crude polysaccharides were obtained. We evaluated the antioxidant activities of crude polysaccharides and deproteinized polysaccharides in vitro by flow injection analysis chemiluminescence (FIA-CL), based on the inhibition effect of their natural antioxidants on the free radical-induced luminol chemiluminescence. Ascorbic acid was used as positive control. At the optimum operational conditions, the antioxidant activity was measured by plotting the inhibition $v s$. the content of samples to calculate the $\mathrm{IC}_{50}$. The results showed that deproteinized polysaccharides showed higher scavenging activities on the reactive oxygen species such as superoxide anion radical, hydroxyl radical and hydrogen peroxide than that of crude polysaccharides, but less than that of ascorbic acid. This suggests that Tussilago farfara is a good natural antioxidant and has the potential to be used in the manufacturing of foods and medicines.
\end{abstract}

Keywords: Flow injection chemiluminescence, Polysaccharides Tussilago farfara L., Antioxidation.

\section{INTRODUCTION}

Reactive oxygen species (ROS) are produced in the cells by cellular metabolism and other exogenous environmental agents. However, the uncontrolled production of ROS plays a significant pathological role in aging, coronary heart disease, cancer, rheumatoid arthritis and atherosclerosis ${ }^{1,2}$. It is well known that many antioxidants can scavenge free radicals and play an important role on protecting human body from harmful effects of ROS. Nowadays, many synthetic antioxidant agents have been developed to remediate oxidative stress. However, the side effects of these synthetic antioxidant agents became major setbacks in combating oxidative stress. Thus, it is necessary to the development and utilization of some natural antioxidants, so that they can protect the human body from free radicals and retard the progress of many chronic diseases ${ }^{3,4}$.

Tussilago farfara L. is a member of the asteraceae family. The flower buds of this plant also known as coltsfoot or "Kwandong Hwa" in China and Korea, have been used as a traditional Chinese herbal medicine for the treatment of bronchitic and asthmatic conditions ${ }^{5}$. It has been reported to have inhibitory activity against nitric oxide synthase ${ }^{6}$, antimicrobial activity ${ }^{7}$ and antagonistic activity on platelet-activating factor receptor ${ }^{8}$. Major chemical components of Tussilago farfara $\mathrm{L}$. are alkaloids ${ }^{9}$, terpenoids ${ }^{10}$, flavonoids ${ }^{11}$, polysaccharides $^{12}$ and essential oils ${ }^{13}$. Previous investigations mainly focused on terpenoids, flavonoids, alkaloids and other ingredients, while the coltsfoot polysaccharides chemistry, biological activity and applications research involving very less.

It is well known that plant polysaccharides have exhibited strong antioxidant properties and can be explored as effective potential antioxidants ${ }^{14,15}$. In addition, polysaccharides extracted from Taraxacum have also shown antioxidant properties of scavenging free radical ${ }^{16}$. Furthermore, the ethyl acetate, $n$-butanol and water extracts from Tussilago farfara L. were found to be high in antioxidant abilities ${ }^{17}$. However, there is little information about the antioxidant properties of polysaccharides from Tussilago farfara L.. Therefore, in this study, we attempt to characterize the antioxidant activities of polysaccharides from Tussilago farfara L. in vitro.

To evaluate the potential antioxidant effects of substances, many in vitro procedures have been employed ${ }^{18-20}$. In this study, we evaluated the antioxidative effect of polysaccharides from Tussilago farfara L. by using a flow injection analysis method (FIA), which was a fast, accurate system for monitoring chemiluminescence (CL) reactions induced by ROS such as superoxide anion radical $\left(\mathrm{O}_{2}^{-\bullet}\right)$, hydroxyl radical $\left({ }^{\bullet} \mathrm{OH}\right)$ and hydrogen peroxide $\left(\mathrm{H}_{2} \mathrm{O}_{2}\right)$. Ascorbic acid was used as positive control.

\section{EXPERIMENTAL}

The flower buds of Tussilago farfara L. were purchased from Taian Pharmacy in Shandong Province, China. D-Glucose 
was purchased from Guizhou di da technology co., LTD. Luminol was purchased from Sigma. Other chemicals and solvents were of analytical grade and purchased from China National Medicine Group Shanghai Corporation (Shanghai, China). Water was prepared doubly distilled.

All solutions were stored at $-4^{\circ} \mathrm{C}$. Luminol solutions were protected from light by a foil wrapper. Prior to use they were allowed to reach room temperature. All the antioxidants solutions were freshly prepared and diluted in doubly distilled water.

The ultra weak luminescence analyzer (IFFM-D, Remex Electronic Institute Limited Co., Xi'an, China), equipped with an eight-channel rotary injection valve and two peristaltic pumps was used to measure chemiluminescence. The photomultiplier tube was used to detect chemiluminescence signal. An IFFL-D flow-injection chemiluminescence analysis software system (Xi'an Remex Electronic equipment Corporate, Xi'an, China) was used to analysis chemiluminescence signal.

Methods: The flow injection manifold used (Fig. 1) and the optimal experimental conditions have been previously described $^{21}$. The antioxidant abilities of antioxidants were measured by the depression of the signal from its uninhibited level and the percentage of inhibition was evaluated in each case as follows:

$$
\% \operatorname{lnh}=\frac{I_{\text {max }}-I_{\text {min }}}{I_{\text {max }}} \times 100 \%
$$

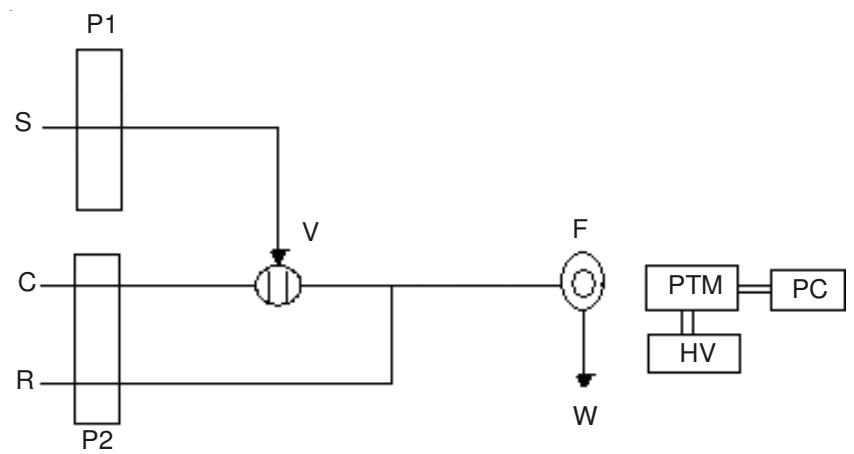

Fig. 1. Diagram of the flow system used in the experiments. S, sample (antioxidant or water ); C,oxidant ; R, luminol; P, Peristaltic pump; $\mathrm{V}$, injection valve; F, chemiluminescence flow cell; PMT, photomultiplier tube; HV, negative high-voltage supply; PC, computer; W, waste solution

Inhibition curves, used to determine the $\mathrm{IC}_{50}$, were represented by plotting the content of samples in each solution $v s$. the $\% \operatorname{lnh}$. The $\mathrm{IC}_{50}$ represented the amount of sample that produced a chemiluminescence inhibition of $50 \%$. Results were the mean values of three replicates of the same sample.

\section{Antioxidant assays}

Superoxide scavenging activity: Superoxide radicals were generated by the autoxidation of pyrogallol. The concentration of pyrogallol represented the concentration of the radicals. The optimal working conditions were as follows: $0.25 \mathrm{mmol} / \mathrm{L}$ pyrogallol in $1 \mathrm{mmol} / \mathrm{L}$ hydrochloric acid, 0.40 $\mathrm{mmol} / \mathrm{L}$ luminol and $0.10 \mathrm{~mol} / \mathrm{L}$ carbonate buffer at $\mathrm{pH} 9.95$.

Hydroxyl radicals scavenging activity: Hydroxyl radicals were generated by Fenton reaction. The concentration of the radicals was represented by the potassium ferrocyanide used to generate them. The optimal working conditions were as follows: $0.26 \mathrm{mmol} / \mathrm{L}$ potassium ferrocyanide, $0.10 \mathrm{mmol} / \mathrm{L}$ luminol, $0.20 \%$ hydrogen peroxide and $\mathrm{KH}_{2} \mathrm{PO}_{4}-\mathrm{NaOH}$ buffer at $\mathrm{pH} 7.20$.

Hydrogen peroxide scavenging activity: In alkaline conditions, luminol is oxidized for luminescence by hydrogen peroxide and the luminous intensity is proportional to the content of hydrogen peroxide. The decreased chemiluminescence intensity can reflect the antioxidant abilities of samples. Hydrogen peroxide was prepared daily and protected from light by a foil wrapper. The optimal working conditions were as follows: $0.30 \%$ hydrogen peroxide, $0.20 \mathrm{mmol} / \mathrm{L}$ luminol and $0.10 \mathrm{~mol} / \mathrm{L}$ carbonate buffer at $\mathrm{pH} 9.60$.

Extraction procedure: The flower buds of Tussilago farfara $\mathrm{L}$. were air-dried at $50{ }^{\circ} \mathrm{C}$ and crushed up (20 mesh), then degreased with $95 \%$ ethanol. The final powders $(5 \mathrm{~g})$ were extracted in a conical flask with cover by ultrasonic treatment, with $125 \mathrm{~mL}$ distilled water, at $70{ }^{\circ} \mathrm{C}$ and $90 \mathrm{kHz}$, for $40 \mathrm{~min}$. The extracted slurry was centrifuged at $4200 \mathrm{rpm} /$ min for $20 \mathrm{~min}$ to collect the supernatant and the insoluble residue was treated again for two times as mentioned above. The supernatant was incorporated and concentrated to onetenth of initial volume using a rotary evaporator at $55^{\circ} \mathrm{C}$ under vacuum. The resulting solution was mixed with three volumes of dehydrated ethanol and kept overnight at $4{ }^{\circ} \mathrm{C}$. Then the solution was centrifuged at $4200 \mathrm{rpm} / \mathrm{min}$ for $20 \mathrm{~min}$, washed with dehydrated ethanol, acetone and diethyl ether respectively. The precipitate was vacuum dried until its weight was constant, then we obtained the sample of crude polysaccharides.

Deproteinization and decolorization of polysaccharides: The sample of crude polysaccharides was dissolved by distilled water and a solution of $10 \mathrm{mg} / \mathrm{mL}$ was prepared. Sevage method was chosen as the optimal method in the process of deproteinization. The sevage reagent (chloroform: $n$-butyl alcohol $=4: 1), 25 \mathrm{~mL}$, was added into the sample solution $(25 \mathrm{~mL})$. Then the solution was mixed at $3000 \mathrm{rpm} / \mathrm{min}$ by homogenizer for $20 \mathrm{~min}$ and was centrifuged at $3000 \mathrm{rpm} /$ min for $10 \mathrm{~min}$ to collect the supernatant. The insoluble residue was treated again for six times as mentioned above. The supernatant was incorporated and stored at $4{ }^{\circ} \mathrm{C}$ for further decolorizing.

The XD-5 resin was used to decolorize polysaccharides. The pretreated XD-5 resin $(20 \mathrm{~mL})$ was filled in the column by wet-packing method. The sample was $2 \mathrm{BV}$ with the current velocity of $1.5 \mathrm{BV} / \mathrm{h}$ meanwhile the sample mass concentration was $5 \mathrm{mg} / \mathrm{mL}$. Then the column was washed with distilled water of $2 \mathrm{BV}$ and the eluent was collected. The eluent was concentrated and freeze-dried to a powder form, then we obtained another sample of polysaccharides which were deproteinized and decolorized.

Determining content of polysaccharides: Total polysaccharides concentration was measured by phenol-vitriol method. Briefly, four grams of the sample was dissolved by $100 \mathrm{~mL}$ distilled water. The supernatant was collected for the determination of polysaccharides. One milliliter of the supernatant was accurately taken and filled into a $10 \mathrm{~mL}$ cuvette. Then $0.5 \mathrm{~mL}, 6 \%$ phenol was added into the cuvette, shaken. Then $2.5 \mathrm{~mL}$ vitriol was filled into the mixture in cuvette, shaken and was left to stand for $0.5 \mathrm{~h}$ at room temperature. At 
last, absorbance was read at the wavelength of $490 \mathrm{~nm}$. At the same time, the wash solution was measured as blank control in an identical way. The content of polysaccharide was expressed as glucose equivalents, using a standard curve of a freshly prepared glucose solution.

\section{RESULTS AND DISCUSSION}

It is well known that superoxide radical is harmful to cellular components as a precursor of the more ROS, contributing to the various diseases such as mutagenesis, carcinogenesis, inflammation and tissue injury by circulatory disturbance. We evaluated the superoxide radical scavenging activity of polysaccharides from Tussilago farfara L. based on pyrogallol/ luminous system. Fig. 2 showed a typical chart recorder trace of a continuous chemiluminescence signal from pyrogallol and luminol ( $\mathrm{pH} \mathrm{10)}$ and the effect of a sequence of injections of water and crude polysaccharides. Chemiluminescence was inhibited by crude polysaccharides, as shown in Fig. 2. Fig. 3 illustrated the superoxide radical-scavenging ability of $1,1.3$, $1.9,2.5,3.1,3.8$ and $4.4 \mathrm{mg} / \mathrm{L}$ of crude polysaccharides and polysaccharides in comparison to $0.8,1,1.5,2,2.5,3,3.5 \mathrm{mg} /$ $\mathrm{L}$ of ascorbic acid. At all the concentrations, the polysaccharide

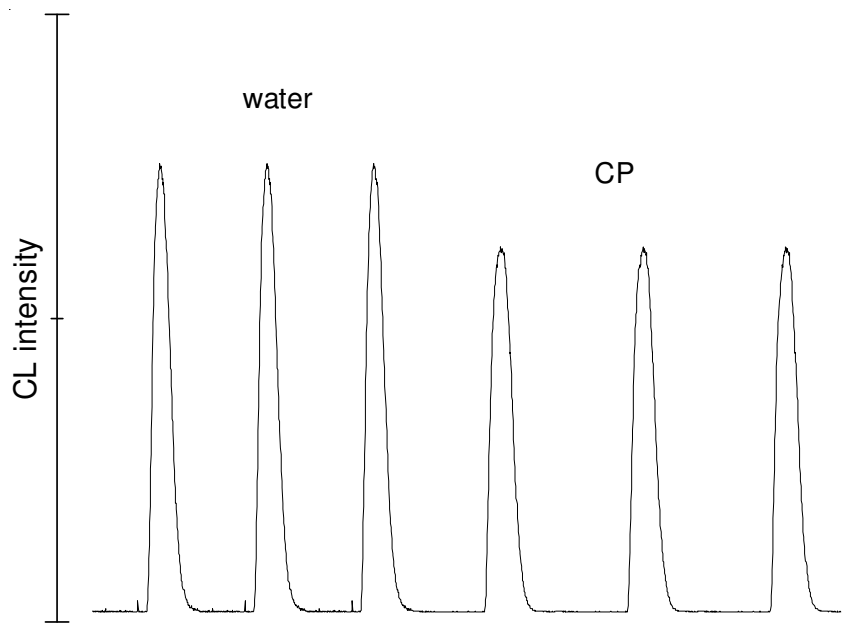

Fig. 2. Effect of crude polysaccharides (CP) on chemiluminescence intensity

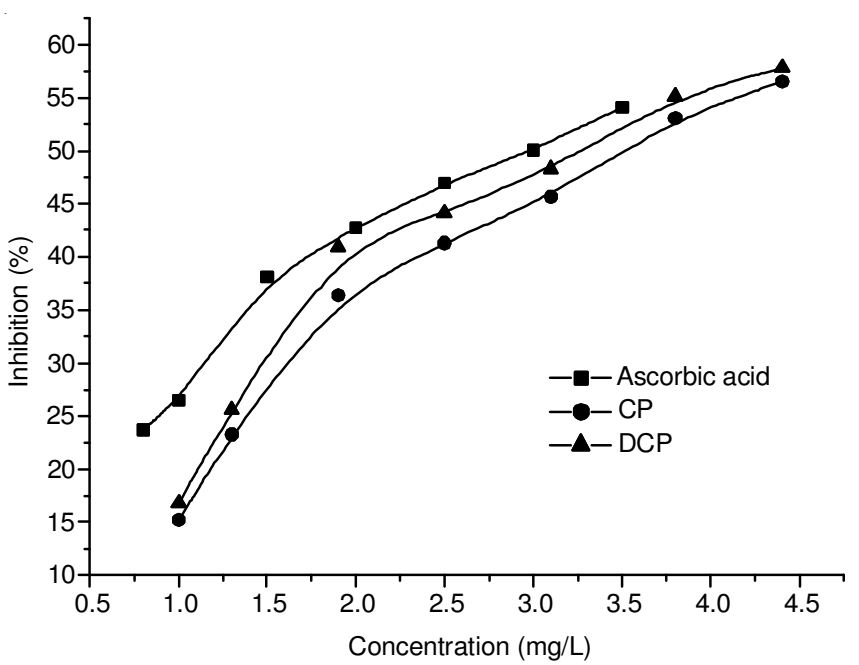

Fig. 3. Scavenging abilities on superoxide radicals of crude polysaccharides, polysaccharides and ascorbic acid samples exhibited varying degrees of antioxidant activity. The $\mathrm{IC}_{50}$ value was $3.54,3.26$ and $2.96 \mathrm{mg} / \mathrm{L}$ for the samples of crude polysaccharides, polysaccharides and ascorbic acid, respectively (Table-1). Low values of $\mathrm{IC}_{50}$ implied higher antioxidant capacity ${ }^{22}$. Thus the antioxidant potency order was ascorbic acid $>$ polysaccharides $>$ crude polysaccharides. The results indicated that polysaccharides and crude polysaccharides exhibited a significant scavenging activity on superoxide radicals. However, the inhibiting ability was lower than that of ascorbic acid.

Scavenging ability on hydroxyl radicals: Hydroxyl radical can easily cross cell membranes and react with most biomolecules such as carbohydrates, lipids, proteins and DNA in cells and cause tissue damage or cell death. Thus, removing ${ }^{\circ} \mathrm{OH}$ is important for the protection of living systems. Fig. 4 showed the percentage ${ }^{\circ} \mathrm{OH}$ scavenging effects of crude polysaccharides and polysaccharides at the dose of $0.3,0.5,0.8,1,1.3,1.9,2.5$ $\mathrm{mg} / \mathrm{L}$. At the test concentrations, crude polysaccharides and polysaccharides exhibited scavenging activity on hydroxyl radicals in a concentration-dependent manner. The $\mathrm{IC}_{50}$ value was $0.99,0.80$ and $0.54 \mathrm{mg} / \mathrm{L}$ for crude polysaccharides, polysaccharides and ascorbic acid, respectively (Table-1). The results indicated that polysaccharides showed slightly higher activity on ${ }^{\bullet} \mathrm{OH}$ than that of crude polysaccharides, but less than that of ascorbic acid.

\begin{tabular}{|c|c|c|c|}
\hline \multicolumn{4}{|l|}{$\begin{array}{c}\text { TABLE } 1 \\
\text { IC }_{50} \text { VALUES OF POLYSACCHARIDES }\end{array}$} \\
\hline & \multicolumn{3}{|c|}{$\mathrm{IC}_{50}(\mathrm{mg} / \mathrm{L})$} \\
\hline & $\mathrm{CP}$ & DCP & $\begin{array}{l}\text { Ascorbic } \\
\text { acid }\end{array}$ \\
\hline Scavenging ability on superoxide radical & 3.54 & 3.26 & 2.96 \\
\hline Scavenging ability on hydroxyl radicals & 0.99 & 0.80 & 0.54 \\
\hline Scavenging ability on hydrogen peroxide & 2.35 & 2.11 & 0.67 \\
\hline
\end{tabular}

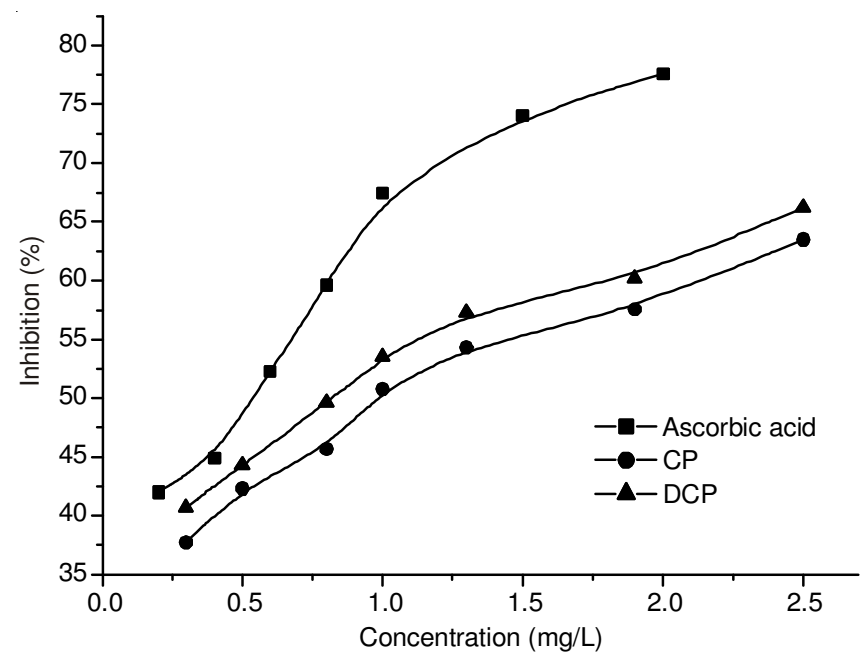

Fig. 4. Scavenging abilities on hydroxyl radicals of crude polysaccharides, polysaccharides and ascorbic acid

Scavenging ability on hydrogen peroxide: In the mammalian organism hydrogen peroxide has a central position within the ROS family. Its formation by several reactions and its controlled inactivation is the basis of 'redox homeostasis" 23 . 
Fig. 5 showed that the inhibiting effects on the hydrogen peroxide of the tested samples were concentration-dependent. The inhibiting effects rose from 25.5 to $51.7 \%$ for crude polysaccharides and 28.1 to $53.61 \%$ for polysaccharides with the concentration increasing from 0.3 to $2.5 \mathrm{mg} / \mathrm{L}$. The $\mathrm{IC}_{50}$ value was $2.35,2.11$ and $0.67 \mathrm{mg} / \mathrm{L}$ for crude polysaccharides, polysaccharides and ascorbic acid, respectively (Table-1). The antioxidant potency order was ascorbic acid $>$ polysaccharides $>$ crude polysaccharides.

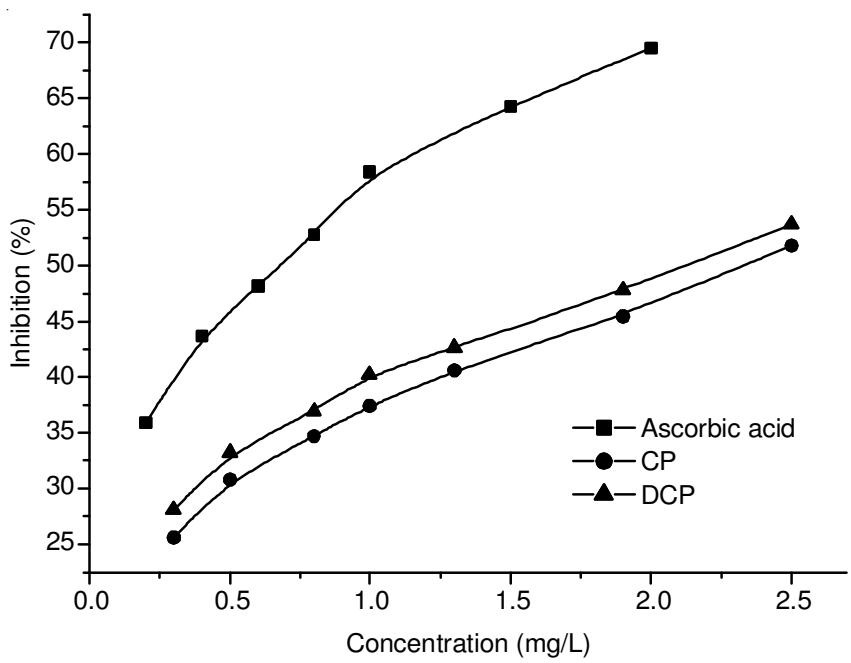

Fig. 5. Scavenging abilities on hydrogen peroxide of crude polysaccharides, polysaccharides and ascorbic acid

Polysaccharides in plants play key biological roles in many life processes. The mechanisms of pharmaceutical effects of bioactive polysaccharides on diseases have been extensively studied and more natural polysaccharides with various curative effects have been tested and even applied in therapies ${ }^{24}$. In the present study, we obtained polysaccharide samples crude polysaccharides and polysaccharides from Tussilago farfara L. and evaluated their antioxidant activities. The results demonstrated that polysaccharides from Tussilago farfara $\mathrm{L}$. could scavenge the ROS such as $\mathrm{O}_{2}{ }^{-\bullet},{ }^{\bullet} \mathrm{OH}$ and $\mathrm{H}_{2} \mathrm{O}_{2}$ effectively. The scavenging activities of the polysaccharides were higher than that of the crude polysaccharides. This suggests that Tussilago farfara L., a good resource of natural antioxidant, has a potential to be used in the manufacturing of foods and medicines and can be developed as a novel potential natural compound for the treatment and prevention of some diseases relating to ROS. We can rationally assume that Tussilago farfara L. has curative effect in traditional medicine partly attributing to the antioxidation of polysaccharides in it.

\section{ACKNOWLEDGEMENTS}

This work was supported by Tai'an Technology Development Program (20132096).

\section{REFERENCES}

1. Y. Sun, Free Radic. Biol. Med., 8, 583 (1990).

2. J.L. Mau, H.C. Lin and C.C. Chen, J. Agric. Food Chem., 50, 6072 (2002).

3. D.H. Luo, Carbohydr. Polym., 71, 544 (2008).

4. $\quad$ N. Singh and P.S. Rajini, Food Chem., 85, 611 (2004).

5. T. Namba, The Encyclopedia of Wakan-Yaku (Vol. II), Hoikusha, Tokyo, p. 525 (1980)

6. J.H. Ryu, Y.S. Jeong and D.W. Sohn, J. Nat. Prod., 62, 1437 (1999).

7. L. Kokoska, Z. Polesny, V. Rada, A. Nepovim and T. Vanek, $J$. Ethnopharmacol., 82, 51 (2002).

8. S.-B. Hwang, M.N. Chang, M.L. Garcia, Q.Q. Han, L. Huang, V.F. King, G.J. Kaczorowski and R.J. Winquist, Eur. J. Pharmacol., 141, 269 (1987).

9. E. Roeder, Pharmazie, 55, 711 (2000).

10. H. Zhi, X. Qin, H. Sun, L. Zhang, X. Guo and Z. Li, Phytochem. Anal., 23, 492 (2012).

11. M.R. Kim, J.Y. Lee, H.H. Lee, D.K. Aryal, Y.G. Kim, S.K. Kim, E.R. Woo and K.W. Kang, Food Chem. Toxicol., 44, 1299 (2006).

12. E. Haaland, A. Hankey, U. Svanholm, A.M. Duffield, A.T. Balaban and J.C. Craig, Acta Chem. Scand., 23, 2546 (1969).

13. N. Suzuki and M. Kikuchi, Yakugaku Zasshi, 112, 571 (1992).

14. Y. Hu, J. Xu and Q.H. Hu, J. Agric. Food Chem., 51, 7788 (2003).

15. Z. Wang and D. Luo, Carbohydr. Polym., 68, 54 (2007).

16. G. Sun, D. Wang, B. Zhao, Z. Guo and T. Zhu, J. Chem. Nat. Comp., 48, 110 (2012).

17. C.T. Li, Y.P. Liu, F.C. He and Y. Li, Chinese J. Natural Med., 10, 260 (2012).

18. B.N. Singh, B.R. Singh, R.L. Singh, D. Prakash, R. Dhakarey, G. Upadhyay and H.B. Singh, Food Chem. Toxicol., 47, 1109 (2009).

19. J.M. Landete, J.A. Curiel, H. Rodríguez, B. de las Rivas and R. Muñoz, Food Chem., 107, 320 (2008).

20. D. Prakash, B.N. Singh and G. Upadhyay, Food Chem., 102, 1389 (2007).

21. C.H. Liu, B.X. Jia, Y.Q. Li, Y.X. Qi, K. Li and Y.R. Guo, Asian J. Chem., 25, 7401 (2013).

22. S. Son and B.A. Lewis, J. Agric. Food Chem., 50, 468 (2002).

23. B. Chance, H. Sies and A. Boveris, Physiol. Rev., 59, 527 (1979).

24. Q.J. Wang and Y.Z. Fang, J. Chromatogr. B, 812, 309 (2004). 